\title{
DESIGN ASPECTS OF THE RF CONTACTS FOR THE LHC BEAM VACUUM INTERCONNECTS
}

\author{
S. Calatroni, F. Caspers, K. Couturier, N. Hilleret, J.R. Knaster, P. Lépeule, M. Taborelli, \\ $\underline{\text { R. Veness }}$, L. Vos, CERN, Geneva, Switzerland
}

\begin{abstract}
The LHC requires a very low longitudinal and transverse beam coupling impedance, in particular at low frequencies. This implies an admissible DC contact resistance of less than $0.1 \mathrm{~m} \Omega$ for the RF contacts inside the vacuum bellows which must carry the image current (up to $50 \mathrm{~A}$ peak) of the beam at each vacuum chamber interconnect. Technological aspects, measurement methods and test results are presented for the contacts which will be used in the LHC. The modified mechanical design and the justifications for specific choices will be discussed
\end{abstract}

\section{INTRODUCTION}

The Large Hadron Collider (LHC) is a $7 \mathrm{TeV}$ protonproton collider currently under construction at CERN. Each of the 8 arcs of the machine will consist of a $2.5 \mathrm{~km}$ long continuous cryostat, operating at $1.9 \mathrm{~K}$. The cryostat contains repeating half-cells comprising three twinaperture dipole magnets and a 'short-straight section' (SSS) with lattice quadrupole and corrector magnets.

These magnets are joined by flexible 'interconnects' to ensure continuity of vacuum, along with local electrical and cryogenic services. A previous paper [1] described the requirements and design principles of the beam vacuum lines of these interconnects. Since then, effort has concentrated on optimising the impedance aspects of the contacts. In addition, the mechanical design has been improved to facilitate manufacture and test, and ease application of the design to non-standard areas of the machine outside the arcs.

\section{IMPEDANCE REQUIREMENTS}

The high intensity beams in the LHC suffer from two instability mechanisms. One is the high frequency single bunch longitudinal instability, the other is the low frequency transverse resistive wall coupled bunch instability. The longitudinal single bunch instability is caused by the inductance of the vacuum chamber due to cross-section variations. The main contributors to the machine inductance are bellows. Most of them (around 1700 per ring) are located in the cold beam vacuum interconnect units. They will be equipped with RF bridges to reduce their inductance. Whilst these bridges are quite efficient in shielding the high frequencies it is not obvious that their resistivity is sufficiently small, especially for such a large machine as the LHC. The average intensity in the LHC requires a powerful transverse feedback system to stabilise the beam and to ensure transverse emittance conservation during the injection process. The transverse emittance is one of the main performance factors for the machine since it determines, together with the intensity and the optics, the luminosity that can be achieved. Its conservation by feedback becomes more difficult when the transverse impedance is larger. Hence a criterion for the resistance of an average RF bridge was defined, based on the following arguments. The contribution of an element (RF bridge) with resistance $R_{r f}$ to the transverse impedance of the machine (based on the classical relationship between transverse and longitudinal impedance) is :

$$
\Delta R_{\perp}=R_{r f} \frac{2 c}{b^{2} \omega_{\beta}},
$$

where $c$ is speed of light, $b=0.02 \mathrm{~m}$ is the inner radius of the element and $\omega_{\beta}$ is the lowest (most unstable) slow wave betatron frequency. The frequency of the most unstable slow wave depends on the optics and is given by:

$$
\omega_{\beta}=(q-n) \frac{c}{R},
$$

where $q$ is the non-integer part of the tune, $n=1$ is the lowest slow wave mode number and $R$ the radius of the machine. It is proposed to operate the machine with $q \sim 0.28$ yielding a value of $\omega_{\beta} / 2 \pi \sim 7 \mathrm{kHz}$. The total budget of the transverse impedance at injection energy was estimated at $100 \mathrm{M} \Omega / \mathrm{m}$. It was conjectured that the contribution of the RF bridges should not exceed $10 \%$ of this value, that is $10 \mathrm{M} \Omega / \mathrm{m}$. The objective of the low frequency resistance for each $\mathrm{RF}$ bridge is then $R_{r f}=0.1 \mathrm{~m} \Omega$. It should be clear that this is really an upper bound. Indeed, the contribution of the RF bridges would jump to $20 \mathrm{M} \Omega / \mathrm{m}$ if the machine is operated at the complementary tune $q \sim 0.72$, i.e. $\omega_{\beta} / 2 \pi \sim 3 k H z$.

\section{CONTACT FINGER DESIGN}

The RF bridge has to provide the resistance specified above with operational offsets of up to $2 \mathrm{~mm}$. In addition, the bridge resistance must not be affected by nonoperational offsets of up to $4 \mathrm{~mm}$. Cryogenic operations on the magnets can give rise to longitudinal displacements of the bridge up to $62 \mathrm{~mm}$. In order to accommodate these movements, an RF bridge has been designed with 30 contact 'fingers' of $\mathrm{CuBe}$, each $0.3 \mathrm{~mm}$ thick. The contact force per finger was specified as $50 \pm 20 \mathrm{~g}$.

\footnotetext{
*raymond.veness@cern.ch
} 
RF contact fingers are made of $0.3 \%$ beryllium copper alloy (UNS designation C17410) which is selected for its high strength and ductility down to cryogenic temperature (see Table 1). The low Be content (compared with $2 \%$ for the standard C17200 grade) gives improved formability, especially in the TH02 temper. This simplifies manufacture. The alloy contains an acceptable level of Co from the point of view of activation. Furthermore, the low total alloying content improves its electrical conductivity (compared with $25 \% \mathrm{IACS}^{1}$ for $\mathrm{C} 17200$ ); a relevant factor for the reduction of impedance in the LHC. The mechanical, electrical and magnetic properties of alloy C17410 were measured at $293 \mathrm{~K}$ and $4.2 \mathrm{~K}$. They are summarised in Table 1. They fulfil the requirements for the LHC RF contact application. Moreover, alloy C17410 shows a good weldability for electron beam welding and a good adhesion of electrodeposited gold coatings is observed on its surface.

\begin{tabular}{|c|c|c|c|c|c|}
\hline \multirow{3}{*}{$\begin{array}{l}\text { Thermo- } \\
\text { mechanical } \\
\text { state } \\
\text { Chemical } \\
\text { composition } \\
(\mathrm{wt} \%)\end{array}$} & \multicolumn{5}{|c|}{$\begin{aligned} \text { TH02 }= & \text { solution annealed }+ \text { cold worked to } 1 / 2 \\
& \text { hard }+ \text { precipitation hardened }\end{aligned}$} \\
\hline & Be & Co & Al & $\mathbf{F e}$ & $\mathbf{N i}$ \\
\hline & 0.31 & 0.5 & 0.04 & 0.03 & 0.02 \\
\hline $\begin{array}{l}\text { Tensile } \\
\text { properties }\end{array}$ & $\begin{array}{c}\mathbf{T} \\
(\mathrm{K}) \\
293 \\
4.2\end{array}$ & $\begin{array}{c}\mathrm{E} \\
(\mathrm{GPa}) \\
138 \\
-\end{array}$ & $\begin{array}{c}\mathrm{Rp} 0.2 \\
(\mathrm{MPa}) \\
626 \\
740\end{array}$ & $\begin{array}{c}\mathrm{Rm} \\
(\mathrm{MPa}) \\
736 \\
937\end{array}$ & $\begin{array}{c}\mathrm{A} \\
(\%) \\
18.7 \\
37.5\end{array}$ \\
\hline $\begin{array}{l}\text { Electrical } \\
\text { properties }\end{array}$ & \multicolumn{3}{|c|}{$\begin{array}{l}\text { Conductivity } \\
\text { (\%IACS) } \\
53.3\end{array}$} & \multicolumn{2}{|c|}{$\begin{array}{c}\text { Residual } \\
\text { Resistivity Ratio } \\
2.3\end{array}$} \\
\hline $\begin{array}{l}\text { Magnetic } \\
\text { properties }\end{array}$ & \multicolumn{2}{|c|}{$\begin{array}{c}\mathrm{T} \\
(\mathrm{K}) \\
\text { From } 4.5 \text { to } 300\end{array}$} & $\begin{array}{c}\mathrm{H} \\
(\mathrm{Oe}) \\
100\end{array}$ & \multicolumn{2}{|c|}{$\begin{array}{c}\text { Static Susceptibility } \\
\text { (SI) } \\
\text { About } 5.10^{-4}\end{array}$} \\
\hline
\end{tabular}

Table 1: General properties of beryllium copper alloy C17410.

Although the $\mathrm{C} 17410 \mathrm{CuBe}$ alloy satisfies all the necessary mechanical requirements, its electrical contact resistance on pure copper is orders of magnitude larger than the value required by the LHC specifications. The resistance has thus to be lowered by a suitable plating of the two sides of the contact. The choice of the material pair for optimum electrical contact follows a few basic guidelines: absence of a surface passivation layer, softness of at least one of the materials to enhance the contact surface. Moreover, for sliding contacts that must undergo several thermal cycles and be able to carry large currents, the requirement of preventing a cold welding has also to be satisfied. After a survey of possible materials, in particular the $\mathrm{Rh} / \mathrm{Ag}$ combination used in PEP-II [2], the combination gold/rhodium has been retained as the ideal one [3]. This combination satisfies all the requirements, and the extreme hardness of $\mathrm{Rh}$ should ideally complement the ductility of Au.

\section{CONTACT MEASUREMENTS}

Several measurements have been carried out to validate the choice of materials. A few other pairs of platings, including the $\mathrm{Ag} /$ stainless steel pair [1] have also been tested for the purpose of confirming the principles of the choices.

Preliminary measurements were made on single fingers rather than a full RF bridge. It has been chosen to plate the $\mathrm{CuBe}$ fingers with $\mathrm{Au}$, to avoid modification of their elasticity by the stiffness of Rh. Both platings have a thickness of $5 \mu \mathrm{m}$, the Rh plating having a flash $\mathrm{Au}$ underlayer for adhesion purposes. The fingers were assembled on a small fibreglass support together with the base of the contact, and acting on it with adjustable force. The contact geometry was identical to the real design of the interconnect. This assembly was installed in a free flow cryostat and the contact resistance measured with the four wire method [4] for different currents and contact forces, between $4.2 \mathrm{~K}$ and $300 \mathrm{~K}$.

The resistance of the contact made of $\mathrm{Au}$ plated $\mathrm{CuBe}$ acting on $\mathrm{Rh}$ plated $\mathrm{Cu}$ has indeed shown the lowest resistance, below $3 \mathrm{~m} \Omega$ in the entire temperature range. This would correspond to $0.1 \mathrm{~m} \Omega$ for the 30 finger RF bridge. As illustrated in Figure 1, the current flowing through the contact has no influence on the contact resistance, the variations being probably due to thermal stresses in the assembly. No influence of the contact force was measurable within the design range for the bridge.

Friction tests at liquid nitrogen temperature and ultra high vacuum have been carried out in a special set-up [5]. A $\mathrm{Rh}$ plated $\mathrm{Cu}-\mathrm{OFE}$ tip slides with the design pressure across an $\mathrm{Au}$ plated $\mathrm{CuBe}$ base The friction stabilises after only a few sliding cycles of $2 \mathrm{~mm}$ in length. After 100 cycles, no signs of cold welding have been detected by measuring the adhesion force when lifting the tip. No signs of peel-off have been seen either, apart from some $\mathrm{Au}$ transfer onto the Rh plated pin.

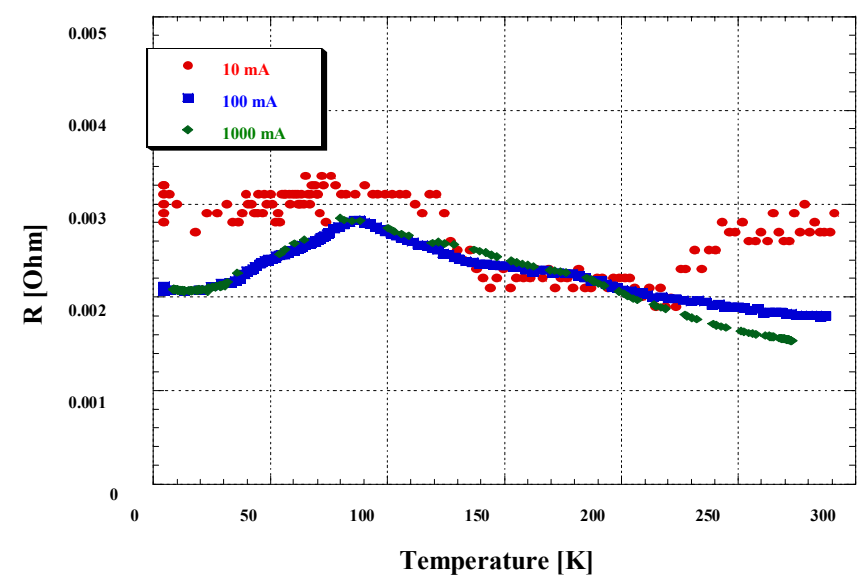

Figure 1: Single Au plated $\mathrm{CuBe}$ contact finger on a $\mathrm{Rh}$ plated $\mathrm{Cu}$ base: contact resistance as a function of temperature for three different current values.

\footnotetext{
${ }^{1}$ International Annealed Copper Standard
} 
Impedance measurements were performed at $4.2 \mathrm{~K}$ to determine the RRR of the combination of $0.3 \mathrm{~mm} \mathrm{C} 17410$ fingers with different $\mathrm{Au}$ coatings (see Table 2). This shows that the overall resistance of the fingers reduce at low temperature, and are significantly improved by increasing the thickness of the gold layer. Due to this effect, the contribution of the fingers can be made negligible compared with the contact resistance at the operating temperature of $1.9 \mathrm{~K}$. A $30 \mu \mathrm{m}$ coating has been provisionally selected for the design. Further studies will determine if this thickness can be reduced to minimise cost.

\begin{tabular}{|l|c|}
\hline Finger & RRR \\
\hline $\mathrm{C} 17410$ & 2.30 \\
\hline $\mathrm{C} 17410+5 \mu \mathrm{m} \mathrm{Au}$ & 3.40 \\
\hline $\mathrm{C} 17410+10 \mu \mathrm{m} \mathrm{Au}$ & 4.75 \\
\hline $\mathrm{C} 17410+30 \mu \mathrm{m} \mathrm{Au}$ & 9.70 \\
\hline
\end{tabular}

Table 2: Variation of Residual Resistivity Ratio (RRR) with Coating Thickness

A number of measurements have been made at room temperature on RF bridge assemblies in order to confirm the results from individual fingers using the four wire method, a 1 A current source and high resistance voltmeter. These tests have shown that the room temperature resistance can be reduced from $\sim 35 \mathrm{~m} \Omega$ for the baseline $\mathrm{Ag} /$ Stainless steel contacts shown in [1] to $\sim 0.15 \mathrm{~m} \Omega$ for the $\mathrm{Rh} / \mathrm{Au}$ contacts. At operating temperature this will go below the $0.1 \mathrm{~m} \Omega$ budget. In addition, changing from $\mathrm{Ag}$ to $\mathrm{Au}$ has given a marked increase in the stability of the resistance with time, probably due to reduced oxide formation on the surface.

Cryogenic measurements of the whole interconnect assembly are in progress.

\section{INTERCONNECT DESIGN}

The mechanical design of the interconnect, shown in figure 2, has changed somewhat from that presented in [1]. The RF bridge, RF bellows and transitions from the hippodrome beam screen shape to circular RF contact shape have all been incorporated into a 'plug-in module'. This module can be assembled, electrically and vacuum tested by the manufacturer. They will only be unpacked, installed and welded with an automatic orbital machine in the LHC tunnel. To assure correct orientation, a positioning pin has been included in the design. The flexible Au coated RF contacts have a special form to minimise the chance of them buckling into the beam aperture in case of unexpected cold welding of a finger.

Inclusion of shape transitions into the plug-in module allows simple design variations to be made for nonstandard zones of the machine, where beam screen shape or beam separation may vary.

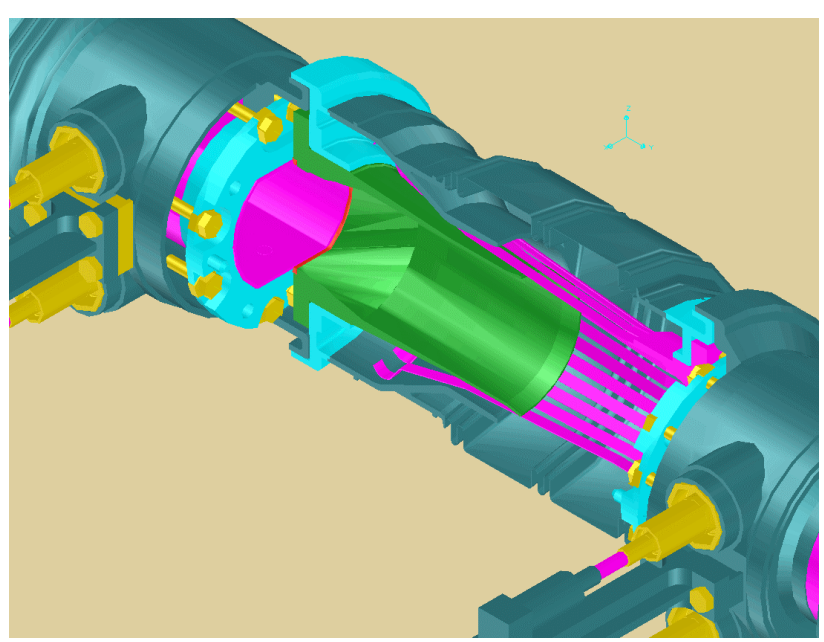

Figure 2: Part-sectioned view of the beam vacuum interconnect, showing plug-in module

\section{SUMMARY}

A very strict requirement for low electrical resistance in the LHC has led to the need for a highly optimised RF bridge design. Using a combination of a high conductivity $\mathrm{CuBe}$ alloy with gold and rhodium coatings has allowed the resistance to be lowered by 2 orders of magnitude from that achieved in the LEP machine. Work is in progress to minimise the contribution of the static contacts between plug-in module and beam screens.

The mechanical layout has also been improved to maximise the testing of sub-assemblies. This will yield improved reliability, which is essential considering the access difficulties to this cryogenic machine.

\section{ACKNOWLEDGEMENTS}

The authors would like to thank the following people: P. Chiggiato investigated the cold welding properties of materials; A. Lasserre and M. Malabaila performed the plating; V. Neyret from IUT, Annecy compiled the materials data; T. Le Mogne from Ecole Centrale Lyon performed the friction tests; G. A. Izquierdo studied the contact surfaces after testing; H. Kos performed the room temperature resistance tests; V. Petrov from IHEP, Protvino made the detailed mechanical design; D. Chauville made mechanical tests and M. Prola-Tessaur prepared the manuscript.

\section{REFERENCES}

[1] Beam Vacuum Interconnects for the LHC Cold Arcs, R. Veness et al., PAC99, New York, May 1999.

[2] Development of a Moveable Plunger Tuner for the High-Power RF Cavity for the PEP-II B Factory, H.D. Schwartz et al, PAC97, Vancouver, May 1997.

[3] Binary Alloy Phase Diagrams, T.B. Massalski Ed., ASM International 1990.

[4] Electronic Instrument Handbook, $2^{\text {nd }}$ Edition (Chapter 13), C.F. Coombs (Editor), 1995 McGraw-Hill.

[5] Analytical tribometer, Ecole Centrale Lyon. 